\title{
Research on the Construction of Fiscal Transparency Evaluation System and Its Test Based on Provincial Level Survey Data of China
}

\author{
NA Ming, Li Ying* \\ School of Economics Hefei University of Technology, Anhui Province, China \\ Jasmine.na@163.com, yingzi0906@126.com
}

\begin{abstract}
Based on the IMF's Manual on Fiscal Transparency, this paper, through defining the connotation and extension of fiscal transparency, taking four dimensions, "budget preparation", "budget execution", "data quality" and "fiscal risk" as first level indices, and selecting 15 observation points, constructs the index system to evaluate China's fiscal transparency. Based on big data method to collect data, adopting information entropy theory, the paper creates an objective method to test the rationality of the constructed fiscal transparency index system. The results show that, the information content contained in budget preparation, budget execution and data quality is relatively high, while the information contained in fiscal risk is relatively low.
\end{abstract}

Index Terms - fiscal transparency, big data, information entropy, evaluation system

\section{Introduction}

The arrival of "big data era" is very important to promote the implementation of transparent government worldwide, and to push government to an unprecedentedly open height. As the ideology of democracy and legal system reform win the support among Chinese people, public fiscal information transparency and the realization of "democratization of data" are significant to strengthen the efficiency and responsibility of the government. Since the 18th National Congress of the Chinese Communist Party, the central government has been proposing the idea of "locking the power in the cage". It expresses the Chinese government is determined to strengthen the supervision and restriction of the ongoing power, and in the meanwhile it is also the resonance of the times and Chinese people. In this context, constructing the evaluation system for fiscal transparency is undoubtedly an important component in the design of the top system.

\section{Literature Review}

In 1998, the International Monetary Fund (IMF) launched the "Manual on Fiscal Transparency", which guides the way of supervision of fiscal transparency worldwide, and subsequently issued "Reports on the Observance of Standards and Codes (ROSCs), which provides data support to judge a country's fiscal condition. Farhan Hameed (2005), from the perspective of information content and easy-going principle, taking four dimensions, "data guarantee", "medium-term budget", "budget execution" and "fiscal risk" as the first level indices, selecting 20 indices to constitute the fiscal transparency evaluation system, evaluated 57 countries' fiscal transparency based on the ROSCs information ${ }^{[1]}$. Jorge Baldrich (2005), based on three dimensions, "fiscal data quality", "budget system function", and "tax policy and clear management", which are totally 9 specific indicators for fiscal transparency evaluation system, analysed 45 countries' fiscal transparency ${ }^{[2]}$. J.E.Alt and D.D.Lassen (2006), from four dimension angels, "information content", "independent verification", "accounting principle of fiscal report system", and "sufficient budget", selected 11 indices to construct the evaluation system, and evaluated the fiscal transparency for OECD's 19 countries ${ }^{[3]}$. Nicol ó Andreula (2009), according to the 45 element indices implied in "Good Practices on Fiscal Transparency" revised by the IMF in 2007, selected 39 indices in the light of three dimensions, "information quality", "function and duty", "public budget", and "information's availability to the public", made evaluations on 82 countries and regions' fiscal transparency ${ }^{[4]}$.

In China, relevant research on monitoring the fiscal transparency system can be counted on one's fingers. Public Policy Center in Shanghai University of Finance and Economics, from 2009 to 2013, taking fiscal information openness and accessibility as the evaluation standards, selected a total of 114 indicators to construct the fiscal transparency evaluation system in the light of three dimensions, "government information openness degree", "information coverage", and "information specification degree" ${ }^{[5]}$. Yu Qiao from Public Administration Institute of Tsinghua University in 2012 and 2013 selected 8 indices, like "structure and function of government", "relationship between government and other public sectors", etc., to construct the fiscal transparency system, and conduct a study on 81 cities ${ }^{[6]}$.

From the above literature review, it can be seen that since the "Manual on Fiscal Transparency" was issued in 2007, scholars overseas have intensively improved and modified their fiscal transparency index systems. In China, Public Policy Center in Shanghai University of Finance and Economics, based on the "Regulations on Open Government Information", made a unprecedented domestic research on assessment of Chinese provincial-level fiscal transparency by comparing whether the government publishes the fiscal information that is required to be open, but this research did not take into consideration the international fiscal transparency standards setting. Because fiscal transparency is a symptom for a specific fiscal system, involving a wide range of measurement, it is 
difficult to assess it (Alesina and Petotti, 1999; Tanzi and Schuknecht, 2000) ${ }^{[6]}$. This paper starts with defining the connotation and extension for fiscal transparency, and then constructs China's fiscal transparency evaluation system based on the fiscal transparency standards required by "Manual on Fiscal Transparency", aiming to provide reference for international fiscal transparency comparison.

\section{The Connotation and Extension of Fiscal Transparency}

Fiscal transparency has no fixed meaning, but at present, the widely quoted definition is from Kopits and Craig (1998) that fiscal transparency mainly refers to openness toward the public at large about government structure and functions, fiscal policy intentions, public sector accounts, and projections. This description vaguely defines the "degree" of fiscal transparency, and also brings difficulty to actual evaluation work. Referring to the fiscal transparency standards proposed by the IMF and OECD and "the Fundamental Principles of Official Statistics" by the UN, this paper describes fiscal transparency as the process that government's fiscal department releases fiscal activity information legally, fully and efficiently, to meet the public's expressly or implied needs for fiscal information, and fiscal transparency degree is the degree to which the public's legal right to know the fiscal information can be satisfied.

The connotation defined by academia is based on "internal homogeneity, and external difference", so the connotation of fiscal transparency is greatly abstract. In practice, the connotation defined for the observed object is allowed to have certain obscurity, but the extension must be specific to ensure the evaluation operation. This paper, based on IMF's 2007 “Good Practices on Fiscal Transparency" which pointed out the basic requirements for the four principles of fiscal transparency, "clarity of roles and responsibilities", “open budget processes", "public' availability of information" and "assurances of integrity", evaluation for the provincial fiscal transparency, due to the provincial level, the organizational structure and the relevant tax laws and regulations do not have distinction, so in the construction of a level indicator system, eliminating the principle. The public availability of this paper reflected through the observation point search mode and quantitative criteria.

Therefore, based on the process of fiscal information's formation, and the guidance of IMF's "Code" and the research of Hameed (2006) ${ }^{[7]}$, this paper, thinks that the extension of fiscal transparency, namely the representation of fiscal transparency, should be embodied by the four aspects.

(1) In fiscal activity, budgeting is essential. Budget preparation should be based on clear objectives of macroeconomic and fiscal policy, containing all fiscal information, letting the public know the role of budgeting to facilitate the supervision (hereinafter referred to as budget preparation).

(2) If problems occur during the budget execution, that will lead budget to be invalid. Therefore, using budget measures, such as internal and external audit, Medium-term budgeting to monitor budget implementation, will improve the budget validity (referred to as budget execution).

(3) It is required to have the measures to ensure data reliability (referred to as data quality). These measures can guarantee that the public, such as citizens, investors, policy analysts, can be easier to understand and analyse budget.

(4) It is required to have fiscal risk assessment statement (referred to as fiscal risk). Although budget is to illustrate the expected revenue and expenditure, the external economic and political environment has uncertainty. Therefore, if the public wants to get an accurate fiscal blueprint, government is supposed to provide the related fiscal risk budget statement.

According to the above analysis, this paper will define the extension of provincial fiscal transparency as budget preparation, budget execution, data quality and fiscal risk, and from the side of social public, the better these four dimensions perform, the higher the fiscal transparency is .

Because the public fiscal management capacity is comparatively weak in China, and information disclosure is still at the starting stage. This paper, in the design of index system, follows the objective principle, scientific principle, forward-looking principle, convenient principle, comprehensive principle and operative principle, and then selects 15 indices to construct the fiscal transparent index system (seen as Table 1).

TABLE I China provincial government transparency evaluation index system

\begin{tabular}{|l|l|l|}
\hline dimension & Reference standard $^{\text {1 }}$ & Observation points \\
\hline Budget preparation(BP) & $2.1 .4,2.1^{2}$ & A1 economic assumptions \\
\hline & 2.1 .2 & A2 policy objectives \\
\hline & 2.1 .3 & A3 Effect of new policy \\
\hline Budget execution (BE) & 4.2 .5 & B1 internal audit \\
\hline & 4.3 & B2 external audit \\
\hline & 2.2 .4 & B3 Final reporting \\
\hline & 2.2 .2 & B4 Mid Year Reporting \\
\hline & $4.1,5.2 .1^{3}$ & C1 data interpretability \\
\hline & 3.2 .2 & C2 Budget classification \\
\hline & 3.3 & C3 release of data \\
\hline & 3.1 .1 & C4 budget data coverage \\
\hline & 3.1 .5 & D1 debt \\
\hline & 3.1 .3 & D2 contingent liabilities \\
\hline & 3.1 .3 & D3 tax expenditures \\
\hline & $1.1 .4 ; 3.1 .3$ & D4 quasi fiscal activities \\
\hline & & \\
\hline
\end{tabular}

This paper selects 15 provincial observation points standing for fiscal transparency, and uses information entropy method to do quantitative analysis on the effectiveness of the constructed index system. As regard to data collection, the paper adopts the big data method of acquiring samples from

\footnotetext{
${ }^{1} 1$ IMF' the Code of Good Practices on Fiscal Transparency.

2 OECD' Best Practices for Budget Transparency

3 IMF' data quality assessment framework
} 
the internet; as regard to quantitative standard, in order to ensure the comparability between observation points, the paper adopts Likert's "five point" scale thought, to quantify the observation points.

\section{Information Entropy Test Method}

\subsection{Information content}

In information theory, information is a form of material existence, and its purpose is to eliminate or reduce the random uncertainty. Thus, information content is the measure of the uncertainty. How to measure is contingent. R.V.L.Hartley (1928) proposed using logarithm information to measure information, believing that information content is the logarithm of the number of its possible value ${ }^{[8]}$. Shannon, the founder of the information theory, furthered the initial definition of information content, introducing the probability theory into the study of information conduction problem and giving a quantitative description of information, which is as follows:

For a discrete information Source A which has an certain amount of information, its information set is $\{a i, i=1,2, \ldots, n\}$. Assume that each piece of information has the equal probability to occur, i.e. $\mathrm{p}=1 / \mathrm{n}$, and if a piece of information corresponding to information content is represented by Function $\varphi\left(a_{i}\right)$, and then the information content can be represented as follows:

$$
\varphi\left(a_{i}\right)=\log _{b} n
$$

Assume that the probability of each piece of information is not equal, namely, $\mathrm{p}_{1}, \mathrm{p}_{2}, \ldots, \mathrm{p}_{\mathrm{n}}$, and $p_{i}=p\left(A=a_{i}\right) \geq 0, \sum_{i=1}^{n} p_{i}=1$. Then the information content can be represented as follows:

$$
\varphi\left(a_{i}\right)=\log _{b}\left(1 / p\left(a_{i}\right)\right)=-\log _{b}\left(a_{i}\right)
$$

where $\mathrm{b}$ is the logarithm bottom, commonly valued 2 , e, 10 , representing information content in Bits, Nat, and Hart. In order to simplify the calculation, this paper uses the natural logarithm, e, as the logarithm bottom with the unit of Nat.

If taking Information $a_{i}$ as a random event, Information Content $\varphi\left(a_{i}\right)$ is an increasing function of $\mathrm{a}_{\mathrm{i}}$, undoubtedly a random variable. $\varphi\left(a_{i}\right)$ is also called self-information of $\mathrm{a}_{\mathrm{i}}$, namely the information content of Output Information $\varphi\left(a_{i}\right)$ to the information receiver.

\subsection{Information entropy}

Self- information is for a single piece of information in an information source; the total content of information is the total value of all information. Generally, the probability of getting all kinds of information is different, and therefore it is necessary to do a statistical average on self-information based on the probability. Based on "(2)", there is

$$
H(U)=E\left(\varphi\left(a_{i}\right)\right)=\sum_{i=1}^{n} p_{i} \log _{b} p\left(a_{i}\right)
$$

According to Shannon's information theory, $H(U)$ is called the information entropy of Information Source U. The concept of entropy is referenced in information theory to do a statistical average on self-information, so information entropy is also regarded as average content of self-information.

There are two special cases. One is that the probability for each piece of information is equal, namely $\mathrm{p}=1 / \mathrm{n}$, and then according to "(1)",

$$
H(U)=E\left(\varphi\left(a_{i}\right)\right)=\sum_{i=1}^{n} p_{i} \log _{b} p\left(a_{i}\right)=\log _{b} n
$$

the then information entropy reaching the maximum. Two is when the probability that a certain piece of information $a_{k}(k \in$ $(1,2, \ldots, n))$ occurs to Information Source $U$ is 1 , and the probability of other information occurring is 0 , the then information entropy reaches 0 .

\subsection{The Average of Information Entropy}

Information entropy provides a unified scientific method for measuring information content. In order for information entropy to measure the information content provided by an information source, relative index is usually used,

$$
\lambda=H_{i} / \mathrm{H}_{i}^{\max }
$$

namely the ratio of information entropy of an information source to the maximum of information entropy ${ }^{[9]}$. However, there is no unified standard how much this ratio reaches would provide effective information content, which brings difficulty to the actual operation. To avoid this problem, this paper uses average information entropy as a standard measure. If information entropy is equal to or is more than the average value, then it can be said that this information source provides more information. For instance, in order to assess a student's academic performance, his score can not only be compared with the highest points, but also can be compared with the average points. If higher than the average, it indicates that the student's academic performance is good, otherwise it indicates that he should work harder.

The information of this study can be considered as a discrete random variable. Let information source state set $U$ equal to $\{\mathrm{a} 1, \mathrm{a} 2 \ldots \mathrm{an}, \mathrm{an}+1\}$, and its probability be equal to $\mathrm{P}=\left\{\mathrm{p}\left(\mathrm{a}_{1}\right), \mathrm{p}\left(\mathrm{a}_{2}\right), \ldots, \mathrm{p}\left(\mathrm{a}_{\mathrm{n}}\right), \mathrm{p}\left(\mathrm{a}_{\mathrm{n}+1}\right)\right\}$, the probability space is expressed as:

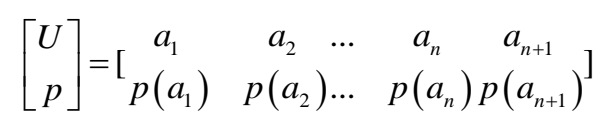

Obviously, $p\left(a_{i}\right) \geq 0, \sum_{i=1}^{n+1} p\left(a_{i}\right)=1$ 。

Based on "(3)", the information entropy of Information Source U is

$$
\begin{aligned}
& H(U)=-\sum_{i=1}^{n+1} p\left(a_{i}\right) \log _{b} p\left(a_{i}\right) \\
& =-\sum_{i=1}^{n} p\left(a_{i}\right) \log _{b} p\left(a_{i}\right)-\left(1-\sum_{i=1}^{n} p\left(a_{i}\right)\right) \log _{b}\left(1-\sum_{i=1}^{n} p\left(a_{i}\right)\right)
\end{aligned}
$$


Using the average value of the function of one variable $\bar{y}=\frac{1}{b-a} \int_{a}^{b} f(x) d x$, then the average value of "(6)" is

$$
\bar{H}_{n+1}=\frac{\iint_{\ldots \tau} \int H_{n+1}(U) d p\left(a_{1}\right) d p\left(a_{2}\right) \ldots \mathrm{d} p\left(a_{n}\right)}{\iint_{\ldots \tau} \int d p\left(a_{1}\right) d p\left(a_{2}\right) \ldots \mathrm{d} p\left(a_{n}\right)}
$$

where $\tau=\left\{\mathrm{p}\left(\mathrm{a}_{1}\right), \mathrm{p}\left(\mathrm{a}_{2}\right), \ldots, \mathrm{p}\left(\mathrm{a}_{\mathrm{n}}\right) \mid p\left(a_{i}\right) \geq 0, \sum_{i=1}^{n} p\left(a_{i}\right)=1\right\}$.

It can be proved that because

$$
H(U)=-\sum_{i=1}^{n+1} p\left(a_{i}\right) \log _{b} p\left(a_{i}\right)=-\frac{1}{\ln b} \sum_{i=1}^{n+1} p\left(a_{i}\right) \ln p\left(a_{i}\right)
$$

$\sum_{i=1}^{n+1} p\left(a_{i}\right)=1$

Then $\iint_{\ldots \tau} \int H_{n+1}(U) d p\left(a_{1}\right) d p\left(a_{2}\right) \ldots \mathrm{d} p\left(a_{n}\right)$

$$
\begin{aligned}
& \frac{1}{\ln b}\left\{\sum_{i=1}^{n} \iint \ldots \tau\left(-p\left(a_{i}\right) \ln p\left(a_{i}\right)\right) d p\left(a_{1}\right) d p\left(a_{2}\right) \ldots d p\left(a_{n}\right)\right. \\
& \left.+\iint_{\ldots \tau} \int\left[-\left(1-\sum_{i=1}^{n} p\left(a_{i}\right)\right) \ln \left(1-\sum_{i=1}^{n} p\left(a_{i}\right)\right)\right] d p\left(a_{i}\right) d p\left(a_{2}\right) \ldots d p\left(a_{n}\right)\right\}
\end{aligned}
$$

Based on Ding Yong (2012 ${ }^{[10]}$, it can be derived that

$$
\bar{H}_{n+1}=\frac{1}{\ln b} \times \frac{(n+1) \frac{1}{(n+1) !} \sum_{i=1}^{n+1} \frac{1}{i}}{1 / n !}=\frac{1}{\ln b} \sum_{i=1}^{n+1} \frac{1}{i}
$$

When $n \geq 2, \frac{\sum_{i=2}^{n} \frac{1}{i}}{\ln b}$ is the monotone increasing function of $\mathrm{n}$, and $\lim _{n \rightarrow \infty} \sum_{i=2}^{n} 1 / i$

When $\mathrm{n}=1, \bar{H}_{n+1}=1 / 2, H^{\max }=\log _{b} n$ and when the unit is Nat, namely $\mathrm{b}=\mathrm{e}$, then $\frac{\bar{H}_{n+1}}{H^{\max }}=\frac{1}{2 \ln 2}=0.7214$.

It can be seen that the average value of information entropy accounts for about $72.14 \%$ of maximum information entropy. The academic circles usually think that if the information entropy of an observation point is more than the average information entropy, it can indicate the information provided by an information source can reflect the subject's activity.

\section{Information Entropy Test Observation Point}

Based on the analysis on information entropy, this paper adopts average information entropy as a measure of information content provided by an information source to evaluate constructed fiscal transparency information, calculates the information content of 15 observation points, and compares the information content with the average information entropy. The specific calculation process is done as follows:

This paper uses Likert "five point" scale method for assignment of the observation points, and all possible values for each observation point is $U=\{0,1,2,3,4\}$, and the average information entropy of all observation points is equal.

$$
\bar{H}_{15}=\frac{1}{\ln b} \times \frac{77}{60}
$$

$\mathrm{b}=\mathrm{e}$, and the average information entropy $\bar{H}_{15}=1.2833$

Then, test the information content on observation points of each dimension in different provinces and cities. Take the information content of the economic assumption observation point, A1, as an example, and it should be calculated as follows:

$$
\begin{aligned}
& p(0)=\frac{11}{30}=0.3667 ; p(1)=\frac{9}{30}=0.3 ; p(2)=\frac{2}{30}=0.0667 \\
& p(3)=\frac{7}{30}=0.2333 ; p(4)=\frac{1}{30}=0.0333
\end{aligned}
$$

Based on "(2)", the information content of A1on a single observation point is

$$
\begin{aligned}
& \varphi(0)=-\ln p(0)=1.0033 ; \varphi(1)=-\ln p(1)=1.204 ; \\
& \varphi(2)=-\ln p(2)=2.7081 ; \varphi(3)=-\ln p(3)=1.4553 ; \\
& \varphi(4)=-\ln p(4)=3.4012
\end{aligned}
$$

According to the above calculation result, it can be proved that Information Content $\varphi\left(a_{i}\right)$ is an increasing function of A1. The highest score is 4 , containing the maximum content of information.

Finally, based on "(3)", the information entropy of A1 in a certain information source can be calculated as $\mathrm{H}_{\mathrm{Al}}(\mathrm{U})=$ 1.3625 .

Thus, the information entropy of every observation point can be calculated. Comparing the information content of 15 observation points (Fig. 1), the information entropy for the three observation points in the dimension of "budget preparation" all exceeds the average information entropy, which means the three observation points contain higher information content. Among them, the information entropy for the observation point, "Effect of new policy", is 1.5496, ranked second in all observation points. There are three quantitative measure standards for this observation point: 1 . the impact of changes in new policy on the current fiscal revenue and expenditure; 2 the impact of changes in new policy on the future fiscal revenue and expenditure; 3 the impact of fiscal revenue and expenditure includes qualitative research and quantitative research. From the perspective of quantitative measure standards, there are great differences in fiscal transparency between provinces and cities in terms of the effect of policy changes on budget preparation.

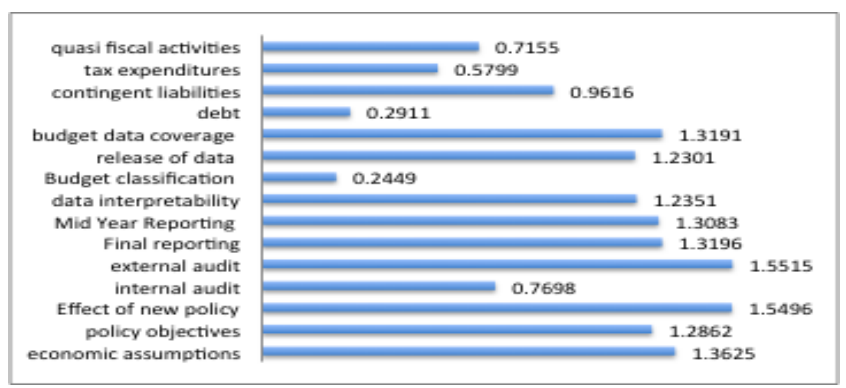

Fig. 1 the entropy on each observation point of fiscal transparency 
In the "budget execution" dimension, the entropy of "external audit" is 1.5515 , containing the largest information content among the 15 observation points, which shows that there is a large transparency difference in the execution of external audit between various provinces and cities. The external audit observation point mainly corresponds to whether the audit institutions will actively fulfil its duty, disclose the negative problems in fiscal report, provide relevant information of taking effective follow-up measures to monitor and correct negative problems, and ensure taxpayers' rights to know. During the data-collecting process, this paper finds that only Yunnan, Chongqing and Guangdong's fiscal audit report made a detailed classification and disclosure of negative problems, listed article by article the audit results of a specific sum of money, and made subsequent tracking of the problems. Many provinces and cities' audit reports are relatively rough, lacking follow-up actions. 7 provinces and cities even did not release their audit reports at all.

In the "data quality" dimension, the average entropy contained by "fiscal data classification" is 0.2446 , the lowest value among the 15 observation points. This observation point mainly corresponds to whether budget expenditure is published based on the classification of economy, sector, function, etc. From our study, in the "Chinese fiscal Yearbook" and provincial fiscal Yearbook, budget expenditure is generally published based on function in various provinces and cities. However, based on economic nature, only Yunnan released its all types of budget expenditure, and based on sector division, only Shanghai did that, which shows that the majority of provinces and cities did not issue relevant information, lead to the observation points containing small content of information. In addition, the information entropy of "internal audit" is 0.7698 , far below the average information entropy.

It is worth mentioning that the information entropy of the four observation points in the dimension of "fiscal risk" is far lower than the average information entropy, containing quite small information content. From a theoretical point of view, only when the 30 provinces and cities in survey have equal probability on the 15 observation points, the information content of this observation point could achieve the maximum value. However, according to the collected data, the 30 provinces and cities discloses little information in the dimension of fiscal risk, such as debt. Information's quantitative measure includes whether or not to publish the information such as government's total volume of asset and liability, and balance sheet, sum volume of asset respectively listed by sector, educational department's total asset and its main classified asset, sum volume of asset respectively listed by educational department's subordinate units; total volume of provincial-level accumulated fiscal debt, and sum volume of domestic debt and external debt; sum volume of government debt respectively classified by term and creditor structure. Hebei released 1 case, Fujian released 4 cases, the remaining
28 provinces and cities did not publish relevant information. However, because this dimension is significant to fiscal transparency, and also a relatively obscure part for government fiscal operation and desired part for people to know, on the basis of forward-looking principle of index system construction, it should still be included in the index system.

\section{Conclusion}

According to the above analysis, this paper gets removed the observation points of low information content, "internal audit" and "classification". Taking into account that the dimension of fiscal risk is significant to of fiscal transparency, and also a relatively obscure part for government fiscal operation and desired part for people to know, on the basis of forward-looking principle of index system construction, this dimension is still included in the index system. Finally, this paper's index system is consisted of four dimensions, budget preparation, budget execution, data quality, fiscal risk, totally 13 observation points. Due to the comprehensive evaluation of fiscal transparency is a huge system, this paper is just an earlystage result, but providing a basis for the subsequent analysis for fiscal transparency.

\section{Acknowledgment}

The results reported in this article were supported by "the National Social Science Fund" (14CTJ007) and "Hefei City's Philosophy and Social Science Planning Project" (HFSK1314D13)

NaMing and LiYing thanks the support of the fund "The Impact of Fiscal Transparency on Corruption from the Perspective of Big Data".

\section{References}

[1] F.Hameed, "Fiscal transparency and economic outcomes," IMF Working Paper WP/2005/ 225

[2] J.E.Alt,D.D.Lassen, "Fiscal transparency, political parties, and debt in OECD countries," European Economic Review, 2006(50), pp. 14031439.

[3] J. Baldrich, "Fiscal transparency and economic performance," http://citeseerx.ist.psu.edu/viewdoc/download?doi=10.1.1.110.1268\&re $\mathrm{p}=$ rep1\&type $=$ pdf.

[4] Nicoló Andreula, Alberto Chong and Jorge Guillén, "Institutional quality and fiscal transparency," Inter-American Development Bank Working Paper, 2009.

[5] Jianghong and Liuxiaobing, "Evaluation on fiscal transparency at provincial level in china," Journal of Shanghai University of Finance and Economics, 2009(2), pp. 50-58.

[6] Liying, "Review on the fiscal transparency," Value Engineering, 2012, (20), pp. 175-177.

[7] Farhan Hameed, "Fiscal transparency and economic outcomes," IMF Working Paper WP/2005/225 .

[8] Tang Yan, "Research on information content of DQAF based on entropy theory," Statistics and Information Forum, 2011,(07), pp. 15-22.

[9] Rodolf Clausius, "The mechanical theory of heat: with its applications to the steam-engine and to the physical properties of bodies," London:John Van Voorst,1867, pp. 251-256.

[10] Dingyong, "Mean information entropy for discrete random variables," Mathematics in Practice and Theory, 2012 (18), pp. 141-14. 